\title{
MUTAGENESIS OF ASPERGILLUS ORYZAE IPT-301 TO IMPROVE THE PRODUCTION OF $\beta$ - FRUCTOFURANOSIDASE
}

\section{Beatriz Guilarte Maresma ${ }^{2}$, Boris Gutarra Castillo ${ }^{1}$, Rubén Cuervo Fernández ${ }^{2}$, Elda Sabino da Silva ${ }^{1}$, Alfredo Eduardo Maiorano $^{1}$, Maria Filomena de Andrade Rodrigues ${ }^{1 *}$}

${ }^{1}$ Laboratório de Biotecnologia Industrial, Instituto de Pesquisas Tecnológicas, Universidade de São Paulo, Sao Paulo, SP, Brasil; ${ }^{2}$ Instituto Cubano de Investigaciones Azucareras-ICINAZ, Habana, Cuba.

Submitted: January 19, 2009; Returned to authors for corrections: June 30, 2009; Approved: September 16, 2009.

\begin{abstract}
Aspergillus oryzae IPT-301, previously reported as a $\beta$-fructofuranosidase producing microorganism, was successfully mutated using UV irradiation at $253.7 \mathrm{~nm}$ followed by the screening of survivors resistant to certain stress conditions. Strains were first subjected to the $\beta$-fructofuranosidase activity assay using a portion from the colony grown in Petri dish as the enzyme source. Seven mutants with $\beta$ fructofuranosidase activity values relative to the parent culture between 140 - 190\% were selected from survivors grown at temperature of $40^{\circ} \mathrm{C}$ or $0.018 \%(\mathrm{w} / \mathrm{v})$ sodium dodecyl sulfate concentration. They were cultivated on a rotary shaker to characterize mycelium and extracellular fructosyltransferase activities. Three mutants named IPT-745, IPT-746 and IPT-748 showed the highest amount of mycelium activity whose values increased $1.5-1.8$ fold, compared with the parent strain. It was found that more than $55 \%$ of total enzyme activity (mycelium- plus extracellular- activity) from these strains was detected in the mycelium fraction. Only one mutant, IPT-747, exceeded the amount of extracellular enzyme exhibited by the parent strain (1.5 times). This mutant also showed the highest value of total fructosyltransferase activity.
\end{abstract}

Key words: Aspergillus oryzae. Mutagenesis. $\quad \beta$-fructofuranosidase. Fructosyltransferase. Fructooligosaccharides. UV irradiation.

\section{INTRODUCTION}

Fructooligosaccharides (FOS) are produced from sucrose by the action of enzymes with transfructosylating activity, which have been classified as $\beta$-D-fructofuranosidases (EC 3.2.1.26) or fructosyltransferases (EC 2.4.1.9) (1,6). Although several microorganisms such as Fusarium sp. (20), Aspergillus sp. $(6,7,8,15,25)$, Aureobasidium sp. $(2,23,28)$, Penicillium sp.
(5), Bacillus sp. (13), Scopulariopsis sp. (12) and Arthrobacter sp. (10) are able to produce these enzymes, the industrial production of FOS depends mainly on fungal enzymes from either Aureobasidium sp. or Aspergillus sp. (27). Therefore, the search for microorganisms with enhanced transfructosylating activity is important in order to obtain these enzymes on a commercial scale.

\footnotetext{
*Corresponding Author. Mailing address: Laboratório de Biotecnologia Industrial, Instituto de Pesquisas Tecnológicas do Estado de São Paulo-IPT, Av. Prof. Almeida Prado 532, 05508-901 Sao Paulo, Brazil.; Tel.: 5511 3767-4829 Fax: 5511 3767-4055.; .; E-mail: filomena@ipt.br
} 
There are many papers concerning the isolation and screening of microorganisms for enzyme production with high transfructosylating activity, but only few of them involved mutagenesis techniques. Classical mutagenesis with physical and/or chemical agents followed by titre test of a large number of isolates has been used successfully to improve the productivity of several fungal metabolites and enzymes $(4,19,22)$. $\alpha$-Amylase overproducing mutant of Aspergillus oryzae, which was obtained by random mutagenesis showed 6.73 times more dextrinizing and 5.13 times more saccharogenic activities than the parent strain (3).

Aspergillus oryzae is generally recognized as a safe (GRAS) microorganism by the Food and Drug Administration and has been widely used to obtain many kinds of enzymes like amylases, cellulases, pectinases, glycosidases, lipases, proteases and peptidases $(3,17)$. Also, the production of FOS using $\beta$-D-fructofuranosidases synthesized by this fungus has been reported $(14,23,24)$.

In a previous work, some strains of filamentous fungi were grown in batch cultures to compare their abilities for the production of $\beta$-fructofuranosidase. Among them, Aspergillus oryzae IPT-301 showed high levels of fructosyltransferase activity. This enzyme also has a high fructosyltransferase activity to hydrolytic activity ratio, which makes it interesting for potential industrial use (8). The main aim of this study is to improve the fructosyltransferase activity showed by the mentioned strain using UV mutagenesis. Mutants isolated under particular stress culture conditions were researched.

\section{MATERIALS AND METHODS}

\section{Microorganism and media}

Aspergillus oryzae IPT-301 from the Instituto de Pesquisas Tecnológicas do Estado de São Paulo (IPT) culture collections was used as the parent strain. All mutants (also deposited in IPT culture collections) and parent strain were grown on Malt Agar slants at $30^{\circ} \mathrm{C}$ for $7-8$ days. Spore suspensions, prepared by adding saline solution onto the slope, were mixed with glycerol up to $10 \%$ concentration and maintained in ultra freezer at $-80^{\circ} \mathrm{C}$.

The liquid assay medium contained (\% w/v): sucrose 3.0, $\mathrm{NaNO}_{3} 0.3, \mathrm{KH}_{2} \mathrm{PO}_{4} 0.2, \mathrm{MgSO}_{4} .7 \mathrm{H}_{2} \mathrm{O} 0.05, \mathrm{MnCl}_{2} .4 \mathrm{H}_{2} \mathrm{O} 0.02$ and $\mathrm{FeSO} 4.7 \mathrm{H} 2 \mathrm{O} 0.001$. The solid assay medium was prepared by dissolving $1.5 \%(\mathrm{w} / \mathrm{v})$ agar in the above medium. The fermentation medium contained $(\% \mathrm{w} / \mathrm{v})$ : sucrose 15.0 , yeast extract $0.5, \mathrm{NaNO}_{3} \quad 0.5, \mathrm{KH}_{2} \mathrm{PO}_{4} \quad 0.2, \mathrm{MgSO}_{4} .7 \mathrm{H}_{2} \mathrm{O} 0.05$, $\mathrm{MnCl}_{2} .4 \mathrm{H}_{2} \mathrm{O} 0.03$ and $\mathrm{FeSO}_{4} 7 \mathrm{H}_{2} \mathrm{O} 0.001$. The $\mathrm{pH}$ of the media was adjusted to 5.5 before sterilization. Effects of hyphal growth restrictors were studied on Petri dishes with solid assay medium containing $0.01-0.10 \%(\mathrm{w} / \mathrm{v})$ sodium deoxycholate (SD) or $0.001-0.015 \%(\mathrm{w} / \mathrm{v})$ sodium dodecyl sulfate (SDS).

\section{Mutagenesis procedure}

The induction of mutagenesis was carried out by UV irradiation at $253.7 \mathrm{~nm}$ using a germicide lamp G15T8 (Sankyo Denki Co, Ltd). A. oryzae IPT-301 survival to the UV-radiation at different irradiation times was determined using both spore suspensions $\left(10^{6}\right.$ spores $\left.\mathrm{ml}^{-1}\right)$ and spores spread on plates containing solid assay medium at a distance of 25.5 and 38.0 cm from the UV lamp, respectively.

In the first stage of mutagenesis, spore suspensions of the parent strain were spread on the dishes with the solid assay medium containing SD $(0.05 \% \mathrm{w} / \mathrm{v})$ as a colony growth restrictor and later exposed to UV irradiation. Survivors were selected for their morphological characteristics. In the second stage, mutants resistant to a toxic SDS concentration were isolated. A similar procedure as indicated above was used but SDS at $0.018 \%(w / v)$ was added to solid assay medium. In the third stage, mutants resistant at high temperature were selected. Twenty milliliters of spore suspension $\left(10^{6}\right.$ spores $\left.\mathrm{ml}^{-1}\right)$ was poured into a dish under agitation using a magnetic bar and irradiated with UV lamp. The surviving spores were inoculated on $100 \mathrm{ml}$ conical flasks containing $10 \mathrm{ml}$ of liquid assay medium and incubated on a rotary shaker at $40^{\circ} \mathrm{C}$ and $200 \mathrm{rpm}$ overnight. Culture broth was suitably diluted and plated on solid assay medium containing SD $(0.05 \% \mathrm{w} / \mathrm{v})$. 
Irradiated samples were kept in the darkness during the whole procedures. All plates were incubated at $30^{\circ} \mathrm{C}$ for $3-4$ days. Colonies which grew on dishes were picked out and subjected to the preliminary $\beta$-fructofuranosidase assay.

\section{Mutants selection for fructosyltransferase activity}

Plate cultures were used in the first selection of $\beta$ fructofuranosidase hyper-producing mutants. The potential mutants and parent strain were individually cultivated on 90 $\mathrm{mm}$ diameter Petri dishes containing $20 \mathrm{ml}$ of solid assay medium and incubated at $30^{\circ} \mathrm{C}$ for 3 days. One disc of $7 \mathrm{~mm}$ diameter was cut from the colony and suspended in $1.2 \mathrm{ml}$ buffer tris-acetate $\mathrm{pH}$ 5.5. The procedure indicated below for $\beta$ fructofuranosidase activity determination was followed.

The strains showing the greatest values of $\beta$ fructofuranosidase activity were cultivated in $250 \mathrm{ml}$ conical flasks, each one containing $50 \mathrm{ml}$ of fermentation medium. Flasks were inoculated with $0.5 \mathrm{ml}$ of a spore suspension containing around $10^{7}$ spores $\mathrm{ml}^{-1}$ and incubated in a rotary shaker at $30^{\circ} \mathrm{C}$ and $200 \mathrm{rpm}$ for $72 \mathrm{~h}$. Mycelia were separated from culture media by vacuum filtration using a $48 \mu \mathrm{m}$ filter and washed four times with distilled water. Mycelium and extracellular fructosyltransferase activities were measured as indicated below.

\section{Analytical methods \\ Cell mass concentration}

Cell mass concentration was determined as mycelium dry weight per volume $\left(\mathrm{g} \mathrm{l}^{-1}\right)$. The samples of fermentation broth were filtered, and the mycelia obtained were washed with distilled water and dried at $105^{\circ} \mathrm{C}$ for 4 hours.

\section{Enzyme activities}

The mycelium and extracellular fructosyltransferase activities were determined from the amount of FOS produced under the following assay conditions: $0.02 \mathrm{~g}$ of wet cells or 0.1 $\mathrm{ml}$ of suitably diluted supernatant were mixed with $3.7 \mathrm{ml}$ of $64 \%(\mathrm{w} / \mathrm{v})$ sucrose solution and $1.2 \mathrm{ml}$ of tris-acetate buffer $0.2 \mathrm{M} \mathrm{pH} 5.5$. The reaction was carried out at $50^{\circ} \mathrm{C}, 100 \mathrm{rpm}$ for
$60 \mathrm{~min}$ and stopped by boiling for $10 \mathrm{~min}$. Products of the reaction mixture were analyzed by high performance liquid chromatography (HPLC). To measure the $\beta$-fructofuranosidase activity, a $7 \mathrm{~mm}$ diameter disc from the colony was used as the enzyme source, the assay conditions were the same as indicated above. The reducing sugars released in the reaction mixture were measured by a dinitrosalicylic acid method (18) and expressed as glucose.

One unit of $\beta$-fructofuranosidase activity was defined as the amount of enzyme required to release $1 \mu$ mole of glucose per minute from sucrose under the above assay conditions. One unit of fructosyltransferase activity was defined as the amount of enzyme that produces $1 \mu$ mole of FOS (1-kestose plus nystose) per minute, under the above assay conditions.

\section{Sugars concentrations}

Sugars were analyzed by HPLC using an Aminex HPX87C (300 x $7.8 \mathrm{~mm}$, Bio-Rad Laboratories) column and a Waters system composed by a 510 pump, a refraction index differential detector and a data processor with register. The column temperature was maintained at $85^{\circ} \mathrm{C}$. Milli-Q water was used as a mobile phase at $0.6 \mathrm{ml} \mathrm{min}{ }^{-1}$ flow rate.

\section{RESULTS}

\section{Effects of sodium deoxycholate and sodium dodecyl sulfate on growth}

Aspergillus oryzae IPT-301 shows a fast growth in solid medium, thus to use a hyphal growth restrictor during the plate assays was necessary. The effect of sodium deoxycholate at different concentrations $(0.01-0.10 \% \mathrm{w} / \mathrm{v})$ on colony size was studied. Values of colony diameter after cultivation for 3, 4 and 5 days in Petri dish are shown in Table 1. The results indicate that an increase of SD concentration caused a significative decrease of colony diameter. At $0.05 \%$ concentration, diameter reduction of $57 \%$ was obtained. This SD concentration was appropriate to obtain isolated single colonies with diameter average of $8.3 \mathrm{~mm}$ at 3 days and it was used in further mutagenesis experiments. Figure 1 exhibits the growth of this 
fungus on solid assay medium containing $\mathrm{SD}$ at $0.05 \%$ concentration (plate b). It can be seen that SD restricted the spread of mycelia on agar medium compared with the control without SD (plate a), so that over 30 colonies can be examined on a single plate.

Table 1. Effect of sodium deoxycholate concentration on the colony size of Aspergillus oryzae IPT-301

\begin{tabular}{|c|c|c|c|}
\hline \multirow{2}{*}{$\begin{array}{c}\text { SD } \\
(\% \mathrm{w} / \mathrm{v})\end{array}$} & \multicolumn{3}{|c|}{ Colony diameter (mm) } \\
\hline & 3 days & 4 days & 5 days \\
\hline 0.00 & $19.1 \pm 0.8$ & $33.4 \pm 1.4$ & $44.0 \pm 2.8$ \\
\hline 0.01 & $16.3 \pm 0.6$ & $25.7 \pm 1.0$ & $35.8 \pm 2.1$ \\
\hline 0.02 & $13.3 \pm 0.7$ & $20.2 \pm 0.7$ & $28.9 \pm 0.9$ \\
\hline 0.03 & $11.1 \pm 0.4$ & $17.0 \pm 0.5$ & $24.7 \pm 0.8$ \\
\hline 0.04 & $9.4 \pm 0.4$ & $15.1 \pm 0.5$ & $21.6 \pm 0.4$ \\
\hline 0.05 & $8.3 \pm 0.3$ & $13.0 \pm 0.4$ & $18.8 \pm 0.8$ \\
\hline 0.06 & $7.3 \pm 0.2$ & $11.1 \pm 0.4$ & $16.2 \pm 0.5$ \\
\hline 0.07 & $6.7 \pm 0.2$ & $10.3 \pm 0.5$ & $15.6 \pm 0.7$ \\
\hline 0.08 & $6.2 \pm 0.2$ & $10.1 \pm 0.3$ & $15.2 \pm 0.3$ \\
\hline 0.09 & $6.1 \pm 0.2$ & $10.0 \pm 0.3$ & $15.0 \pm 0.4$ \\
\hline 0.10 & $5.8 \pm 0.2$ & $10.0 \pm 0.2$ & $14.9 \pm 0.5$ \\
\hline
\end{tabular}

Colony diameter: average of 20 measurements. SD: sodium deoxycholate

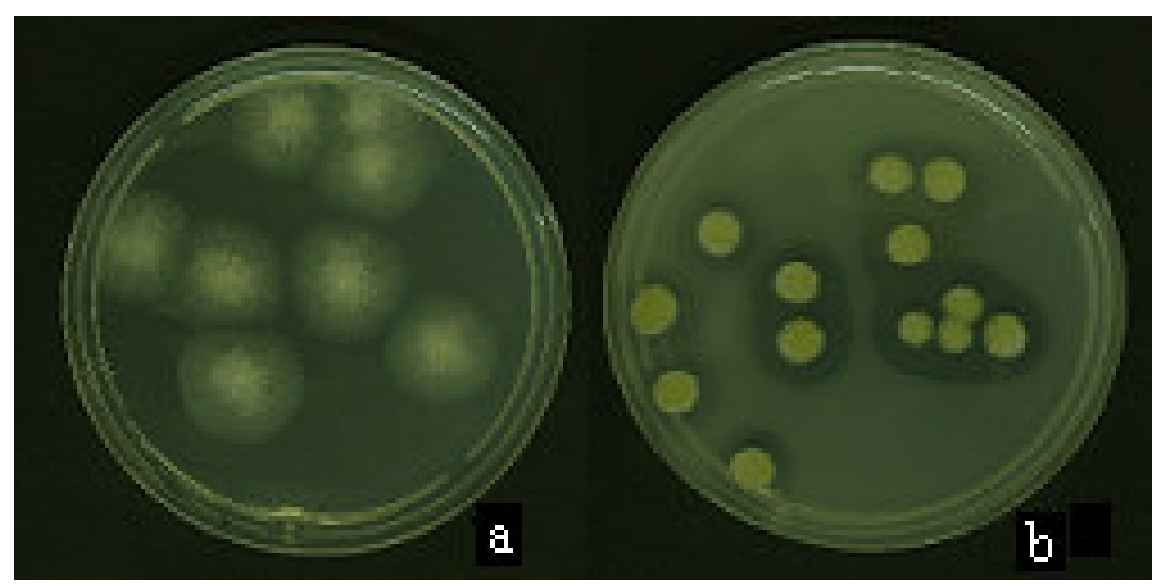

Figure 1. Colonies of Aspergillus oryzae IPT-301 after cultivation for 3 days on solid assay medium containing sodium deoxycholate. a: control; b: $0.05 \%(\mathrm{w} / \mathrm{v})$ concentration 
Guilarte, B. et al.

The influence of sodium dodecyl sulfate as hyphal growth restrictor on the Aspergillus oryzae IPT-301 was studied in the concentration range from 0.001 to $0.015 \%(w / v)$. Colony size was determined after cultivation for 3, 4 and 5 days on Petri dish; results are shown in Table 2. In this range, SDS concentration has a significant effect on the colony growth. At concentration of $0.012 \%$, colonies with diameter average of 7.6 $\mathrm{mm}(60 \%$ of diameter reduction) in 3 days were obtained. Apart from restricting the spread of mycelia, the SDS supplement also affects the spore viability in the range of concentrations evaluated. Figure 2 shows that an increase of SDS concentration over $0.006 \%$ caused a sharp decrease of spore survival, to reach mortality values higher than $95 \%$ at concentration of $0.015 \%$. Consequently, SDS was added to the culture medium to establish toxic conditions to the cells, so mutants that had become resistant to certain level of SDS were screened.

Table 2. Effect of sodium dodecyl sulfate concentration on the colony size of Aspergillus oryzae IPT-301

\begin{tabular}{cccc}
\hline \multirow{3}{*}{$\begin{array}{c}3 \\
\text { SDS }\end{array}$} & \multicolumn{3}{c}{ Colony diameter(mm) } \\
\cline { 2 - 4 } & 3 days & 4 days & 5 days \\
\hline 0.000 & $19.1 \pm 0.6$ & $33.4 \pm 1.4$ & $41.5 \pm 1.4$ \\
0.001 & $16.8 \pm 0.4$ & $31.9 \pm 1.3$ & $37.7 \pm 1.7$ \\
0.002 & $13.6 \pm 0.7$ & $29.9 \pm 1.4$ & $35.5 \pm 1.1$ \\
0.003 & $11.4 \pm 1.0$ & $27.8 \pm 1.6$ & $33.7 \pm 1.3$ \\
0.004 & $10.9 \pm 0.7$ & $26.0 \pm 1.4$ & $31.6 \pm 1.3$ \\
0.005 & $10.7 \pm 1.3$ & $23.9 \pm 0.8$ & $30.4 \pm 1.4$ \\
0.006 & $10.5 \pm 0.9$ & $22.1 \pm 1.1$ & $29.3 \pm 2.6$ \\
0.007 & $10.4 \pm 1.7$ & $21.4 \pm 1.2$ & $28.7 \pm 2.0$ \\
0.008 & $10.0 \pm 0.8$ & $20.7 \pm 0.3$ & $27.7 \pm 1.4$ \\
0.009 & $9.7 \pm 0.9$ & $19.8 \pm 0.3$ & $27.0 \pm 1.4$ \\
0.010 & $9.4 \pm 0.7$ & $18.5 \pm 1.3$ & $25.2 \pm 1.1$ \\
0.012 & $7.6 \pm 0.6$ & $15.6 \pm 0.7$ & $21.1 \pm 1.0$ \\
0.015 & $4.1 \pm 1.3$ & $10.3 \pm 1.2$ & $15.1 \pm 1.6$ \\
\hline
\end{tabular}

Colony diameter: average of 20 measurements. SDS: sodium dodecyl sulfate

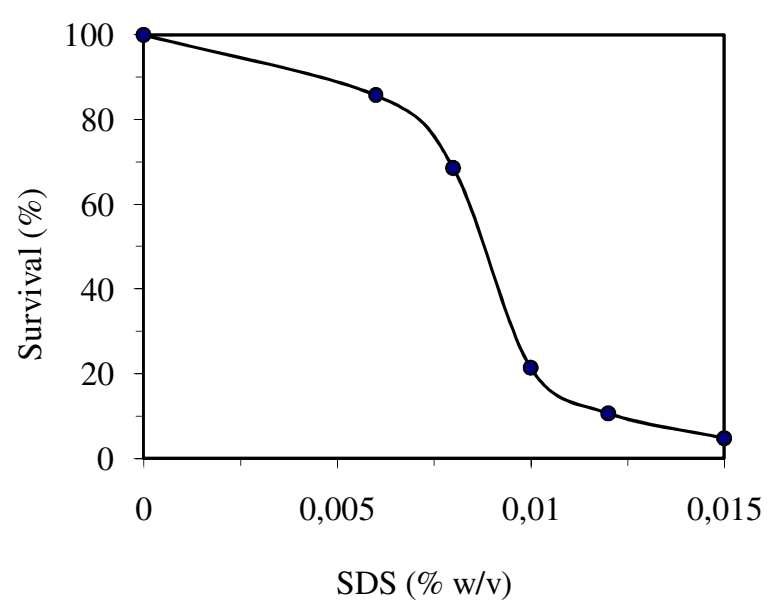

Figure 2. Effect of sodium dodecyl sulfate concentration on surviving of strain Aspergillus oryzae IPT-301 
Isolation of mutants with increased $\boldsymbol{\beta}$-fructofuranosidase activity

Survival of Aspergillus oryzae IPT-301 after treatment with UV irradiation at different times is showed in Figure 3. Survival was reduced by increasing the exposure time, reaching values of spore lethality of $99.99 \%$ at $4 \mathrm{~min}$ and $99.37 \%$ at 5 min after irradiation spores spread on plates containing solid assay medium and spore suspensions, respectively. These results indicate the high sensitivity of this strain to the ultraviolet light and agree with those for Aspergillus oryzae PTCC 5164 which exhibited lethality of $99.9 \%$ at 2 min (3). In the present research, 5 - 6\% survival caused by UV irradiation during 3.5 and $2.5 \mathrm{~min}$ for spore suspensions and spores spread on plates, respectively, was adopted.

The mutagenesis and screening procedures of Aspergillus oryzae IPT-301 were carried out in tree stages with the selection of 317 survivors. All of them were subjected to the preliminary assay of $\beta$-fructofuranosidase activity using plate cultures. Figure 4 shows the distribution of activity values relative to the parent strain $\left(A_{R}\right)$ obtained from potential mutants in each mutagenesis stage. In the first stage, 75 random survivors characteristic of the best growth on solid assay medium were isolated. Although $68.0 \%$ of mutants from this group exhibited $\beta$-fructofuranosidase activity values higher than the parent strain, none presented $A_{R}$ values superior to $130 \%$. In the second stage, 122 strains were selected from survivors grown at temperature of $40^{\circ} \mathrm{C}$; only 4 of them $(3.3 \%)$ reached $A_{R}$ values higher than the above indicated level. Finally, greater amounts $(8.3 \%)$ of mutants with $A_{R}$ values higher than $130 \%$ were screened among the 120 mutants resistant to SDS at $0.018 \%(\mathrm{w} / \mathrm{v})$ concentration. The highest increases of $\beta$-fructofuranosidase activity $(170-190 \%)$ when compared with the parent strain were obtained for two mutants resistant to SDS. They were followed for mutants selected at $40^{\circ} \mathrm{C}$. In this group two strains exhibited the highest $A_{R}$ values between 140 - 150\%. A similar approach has been used by Skowronek \& Fiedurek (26) for isolating inulinase-producing mutants of Aspergillus niger resistant at high temperature.

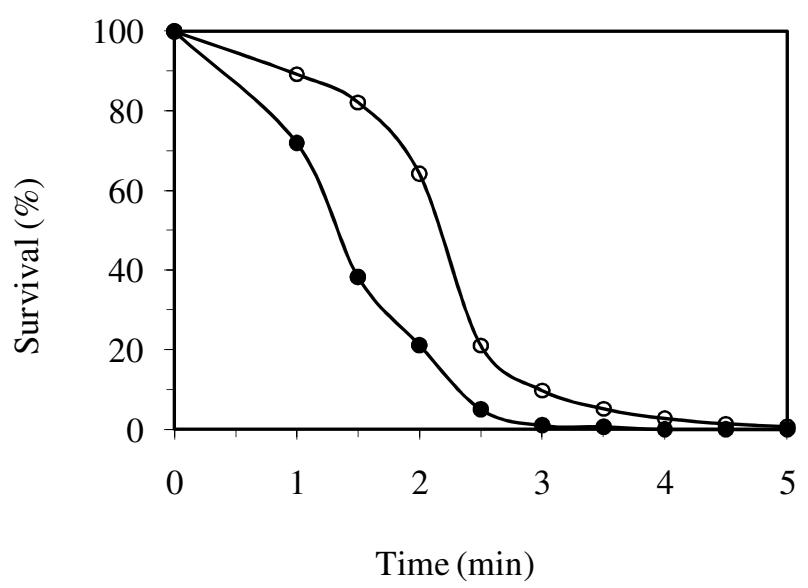

Figure 3. Survival after UV radiation treatment of Aspergillus oryzae IPT-301: (•) spores inoculated on solid assay medium and $(\circ)$ spore suspensions

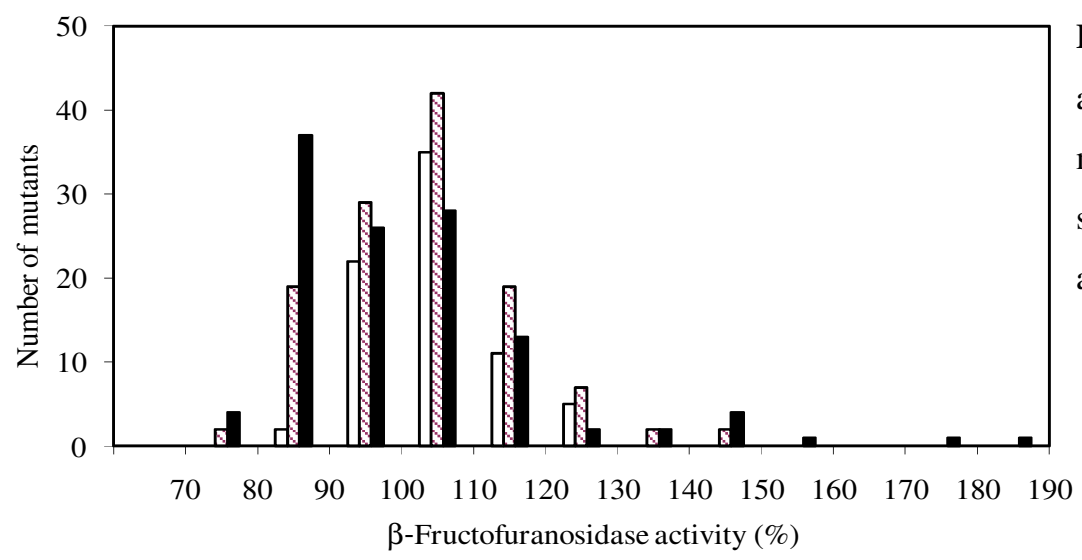

Figure 4. Distribution of $\beta$-fructofuranosidase activity values obtained from the potential mutants of Aspergillus oryzae IPT-301 parent strain. Survivors: $\square$ at random; $\mathbb{N}$ at $40^{\circ} \mathrm{C}$ and at $0.018 \%(\mathrm{w} / \mathrm{v})$ sodium dodecyl sulfate 


\section{Mycelium and extracellular fructosyltransferase activities} of mutants

Among the 317 evaluated strains in the preliminary screening, seven of them with $\beta$-fructofuranosidase activity values relative to the parent culture between $140-190 \%$ were selected. These mutants designated as IPT-744, IPT-745, IPT746, IPT-747, IPT-748, IPT-749 and IPT-754 were cultivated in $250 \mathrm{ml}$ flask on a rotary shaker to characterize enzyme activity with more precision.

Cell growth, sucrose and FOS concentrations in the culture broth after $72 \mathrm{~h}$ of cultivation at $30^{\circ} \mathrm{C}$ are shown in Table 3 . The mutants IPT-745, IPT-746 and IPT-748 presented values of cell mass higher than those obtained by the Aspergillus oryzae IPT-301 parent strain. These results also indicate that the two mutants selected at $40^{\circ} \mathrm{C}$ (IPT-746 and IPT-748) had better growth than the ones resistant to $0.018 \%$ (w/v) SDS. Sucrose, at initial medium concentration of $150 \mathrm{~g} \mathrm{l}^{-1}$ was almost completely used up within $72 \mathrm{~h}$ by each mutant. The $\beta$ fructofuranosidase enzyme synthesized by these strains can react with sucrose and produce FOS, glucose and fructose. Values of FOS concentration calculated by the sum of kestose and nystose were low in fermentation broth due to the fact that reaction conditions are not close to the ones reported as optima for the $\beta$-fructofuranosidase and sucrose was mainly used by the microbial cells for growth and maintenance $(8,14)$.
Mycelium and extracellular fructosyltransferase activities from mutants and A. oryzae IPT-301 parent strain after $72 \mathrm{~h}$ of fermentation are presented in Table 4. Five mutants present values of mycelium specific activity higher than those obtained by the parent strain following the order IPT-746 $>$ IPT-749 > IPT-745 > IPT-748 > IPT-744. Although IPT-749 mutant showed high specific activity (872.3 U per g of dry cell), a low amount of mycelium activity per $\mathrm{ml}$ of culture broth was achieved due to the very poor cell growth of this mutant $(4.1 \mathrm{~g}$ $\left.1^{-1}\right)$. Among the five mutants related above, three of them IPT745 , IPT-746 and IPT-748 can be selected because of the amounts of mycelium activity produced $\left(6.3-7.6 \mathrm{U} \mathrm{ml}^{-1}\right)$. They were about 1.5 - 1.8 times higher than those obtained by the parent strain. It was found that more than $55 \%$ of total enzyme activity (mycelium- plus extracellular- activity) from these strains was detected in the mycelium fraction. Significant differences can be observed when these results are compared with those obtained for parent strain IPT-301 which showed around $33 \%$ of the indicated percentage. Mutants with intracellular activity enhanced are very useful for immobilization of the whole cells. On the other hand, IPT-747 strain was the only mutant that exceeded (1.5 times) the amount of extracellular enzyme exhibited by the parent strain, which yielded $12.9 \mathrm{Uml}^{-1}$. This mutant also showed the highest value of total fructosyltransferase activity $\left(16.9 \mathrm{Uml}^{-1}\right)$.

Table 3. Cell growth, sucrose and FOS concentrations in the culture broth from mutants and Aspergillus oryzae IPT-301 parent strain

\begin{tabular}{|c|c|c|c|c|}
\hline Strain & Screening procedure & $\begin{array}{l}\text { Dry weight } \\
\qquad\left(\mathrm{g} \mathrm{l}^{-1}\right)\end{array}$ & $\begin{array}{l}\text { FOS } \\
\left(\mathrm{g} \mathrm{l}^{-1}\right)\end{array}$ & $\begin{array}{c}\text { Sucrose } \\
\left(\mathrm{g} \mathrm{l}^{-1}\right)\end{array}$ \\
\hline IPT-301 & - & $7.9 \pm 0.4$ & $13.0 \pm 1.0$ & $2.1 \pm 0.8$ \\
\hline IPT-744 & SDS $0.018 \%(\mathrm{w} / \mathrm{v})$ & $7.7 \pm 0.7$ & $4.8 \pm 1.0$ & $1.2 \pm 0.3$ \\
\hline IPT-745 & SDS $0.018 \%(\mathrm{w} / \mathrm{v})$ & $8.0 \pm 0.6$ & $4.3 \pm 0.6$ & $0.9 \pm 0.4$ \\
\hline IPT-746 & Temperature $40^{\circ} \mathrm{C}$ & $8.6 \pm 0.1$ & $10.4 \pm 0.9$ & $3.3 \pm 0.2$ \\
\hline IPT-747 & SDS $0.018 \%(\mathrm{w} / \mathrm{v})$ & $7.4 \pm 0.2$ & $11.2 \pm 0.6$ & $1.7 \pm 0.2$ \\
\hline IPT-748 & Temperature $40^{\circ} \mathrm{C}$ & $9.0 \pm 0.2$ & $11.6 \pm 1.8$ & $3.9 \pm 0.9$ \\
\hline IPT-749 & SDS $0.018 \%(\mathrm{w} / \mathrm{v})$ & $4.1 \pm 0.9$ & $3.5 \pm 0.5$ & $0.6 \pm 0.2$ \\
\hline IPT-754 & SDS $0.018 \%(\mathrm{w} / \mathrm{v})$ & $5.9 \pm 0.6$ & $2.8 \pm 0.6$ & $0.7 \pm 0.2$ \\
\hline
\end{tabular}

SDS: sodium dodecyl sulfate. FOS: 1-kestose plus nystose. Values represent the means of 18 and 6 cultures at $30^{\circ} \mathrm{C}$ during $72 \mathrm{~h}$ for parent strain and each mutant, respectively. 
Table 4. Mycelium and extracellular fructosyltransferase activities from mutants and Aspergillus oryzae IPT-301 parent strain

\begin{tabular}{|c|c|c|c|c|c|}
\hline \multirow{2}{*}{ Strains } & \multicolumn{3}{|c|}{ Mycelium activity } & \multicolumn{2}{|c|}{ Extracellular activity } \\
\hline & Specific $A_{T}\left(U g^{-1}\right)$ & $\mathbf{A}_{\mathrm{T}}\left(\mathbf{U} \mathbf{m l}^{-1}\right)$ & Relative $A_{T}(\%)$ & $\mathbf{A}_{\mathrm{T}}\left(\mathbf{U ~ m l}^{-1}\right)$ & Relative $A_{T}(\%)$ \\
\hline IPT-301 & $545.2 \pm 17.1$ & 4.3 & 100.0 & $8.6 \pm 1.3$ & 100.0 \\
\hline IPT-744 & $611.3 \pm 22.9$ & 4.7 & 110.4 & $4.8 \pm 0.8$ & 56.0 \\
\hline IPT-745 & $780.7 \pm 25.2$ & 6.3 & 146.0 & $4.3 \pm 1.2$ & 50.2 \\
\hline IPT-746 & $878.9 \pm 36.3$ & 7.6 & 176.8 & $6.1 \pm 0.6$ & 70.9 \\
\hline IPT-747 & $537.0 \pm 24.2$ & 4.0 & 92.8 & $12.9 \pm 1.3$ & 150.2 \\
\hline IPT-748 & $722.0 \pm 37.5$ & 6.5 & 152.5 & $2.7 \pm 0.5$ & 31.3 \\
\hline IPT-749 & $872.3 \pm 26.5$ & 3.6 & 84.2 & $5.6 \pm 1.2$ & 65.8 \\
\hline IPT-754 & $569.4 \pm 14.5$ & 3.3 & 78.2 & $4.0 \pm 0.9$ & 46.6 \\
\hline
\end{tabular}

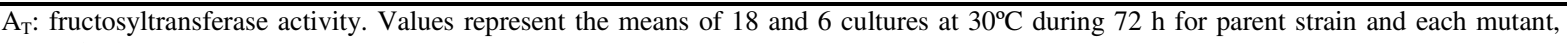
respectively

\section{DISCUSSION}

The results presented above show that it is possible to increase the yield of $\beta$-fructofuranosidase enzyme from Aspergillus oryzae IPT-301 using UV mutagenesis techniques followed by selection of survivors resistant to the particular stress conditions assayed.

A supplement of sodium deoxycholate restricted the spread of Aspergillus oryzae IPT-301 mycelia on solid assay medium. Concentration of $0.05 \%(\mathrm{w} / \mathrm{v})$ was suitable to obtain optimal colony size and to observe the morphological characteristics of more than 30 survivors in each dish. SD sensitivity varies from fungus specie to another. In experiments made with Rhizopus sp. at concentration lower than $0.1 \%$ no significant colony size reductions were obtained (4). Researches with a Penicillium funiculosum strain showed $61 \%$ reduction of the colony diameter at $0.075 \%$ concentration (11). On the other hand, SD at $0.02 \%$ has been sufficient for reduction of colonies of some species of Aspergillus $(9,26)$.

The preliminary evaluation of hyper-producing mutants using a portion from the colony grown in Petri dish as the enzyme source gave reliable indication of elevated $\beta$ - fructofuranosidase activities. Moreover, another advantage of this procedure is that the number of required long-time $\beta$ fructofuranosidase assays using shaker flask cultures was reduced.

The most active mutant (IPT-746) selected from strains resistant at temperature of $40^{\circ} \mathrm{C}$, showed an increase in mycelium fructosyltransferase activity around 1.8 fold in relation to the parent strain. This result can be compared with the one reported for inulinase production by Aspergillus niger $13 / 36$. A mutant from this fungus also resistant at temperature of $40^{\circ} \mathrm{C}$ reached inulinase activity about 1.6 fold bigger than the parent strain (26). On the other hand, the most active mutant (IPT-747) selected from strains resistant at $0.018 \%$ sodium dodecyl sulfate concentration showed extracellular fructosyltransferase activity 1.5 times higher than those obtained by the parent strain. Resistance to several metabolic inhibitors has been tested to isolated biochemical mutants with enhanced enzyme production. Aspergillus niger mutant with increases of the extra and intracellular catalase activities around 2.0 and $2.6 \%$ respectively, was isolated from medium containing antimycin A (9). Also, the resistance to 2-deoxy-Dglucose, a toxic glucose analogue, has been used as a criterion 
Guilarte, B. et al.

to select mutants showing increased yield of $\beta$ fructofuranosidase $(21), \quad \alpha$-amylase $\quad(3,22), \quad$ glucose-6phosphate dehydrogenase (16), catalase and glucose oxidase (9).

\section{ACKNOWLEDGEMENT}

Authors gratefully acknowledge The State of São Paulo Research Foundation (FAPESP) for providing financial support and CNPq for scholarship for Boris Gutarra Castillo.

\section{REFERENCES}

1. Antošová, M.; Polakovič M. (2001). Fructosyltransferases: The enzymes catalyzing production of fructooligosaccharides. Chem. Pap. 55, 350358 .

2. Antošová, M.; Polakovič, M.; Slovinská, M.; Madlová, A.; Illeová, V.; Báleš, V. (2002). Effect of Sucrose Concentration and Cultivation Time on Batch Production of Fructosyltransferase by Aureobasidium pullulans CCY 27-1-1194. Chem. Pap. 56, 394-399.

3. Azin, M.; Noroozi, E. (2001). Random mutagenesis and use of 2-deoxyD-glucose as antimetabolite for selection of $\alpha$-amylase-overproducing mutants of Aspergillus oryzae. World J. Microb. Biotech. 17, 747-750.

4. Bai, D.M.; Zhal, X.M.; Li, X.G.; Xu, S.M. (2004). Strain improvement of Rhizopus oryzae for over-production of $\mathrm{L}(+)$-lactic acid and metabolic flux analysis of mutants. Biochem. Eng. J. 18, 41-48.

5. Barthomeuf, C.; Pourrat, H. (1995). Production of high-content fructooligosaccharides by an enzymatic system from Penicillium rugulosum. Biothecnol. Lett. 17, 911-916.

6. Chien, C.S.; Lee, W.C.; Lin, T.J. (2001). Immobilization of Aspergillus japonicus by entrapping cells in gluten for production of fructooligosaccharides. Enzyme Microbial. Technol. 29, 252-257.

7. Cuervo, R.; Guilarte, B.; Juárez, A.; Martínez, J. (2004). Production of fructooligosaccharides by $\beta$-fructofuranosidase from Aspergillus sp $27 \mathrm{H}$. J. Chem. Technol. Biotechnol. 79, 268-272.

8. Cuervo, R.; Ottoni, C.A.; Sabino, E.; Saito, R.M.; Carter, J.M.; Magossi, L.R.; Alves, M.A.; Rodrigues, M.F.A.; Guilarte, B., Maiorano, A.E. (2007). Screening of $\beta$-fructofuranosidase-producing microorganisms and effect of $\mathrm{pH}$ and temperature on enzymatic rate. Appl. Microbiol. Biotechnol. 75, 87-93.

9. Fiedurek, J.; Gromada, A. (1997). Selection of biochemical mutants of Aspergillus niger with enhanced catalase production. Appl. Microbiol. Biotechnol. 47, 313-316.

10. Fujita, K.; Hara, K.; Hashimoto, H.; Kitahata, S. (1990). Transfructosylation catalyzed by $\beta$-Fructofuranosidase $\mathrm{I}$ from Arthrobacter sp.K-1. Agric. Biol. Chem. 54, 2655-2661.
11. Guilarte, B.; Puente, L.; Cuervo, R.; Vallín, C. (1986). Efecto de algunos inhibidores del crecimiento hifal sobre una cepa de Penicillium funiculosum. Academia de Ciencias de Cuba, Instituto de Química y Biología Experimental, ISSN 0138-6220.

12. Hatakeyama, Y.; Takeda, H.; Ooi, T.; Kinoshita, S. (1996). Kinetic Parameters of $\beta$-Fructofuranosidase from Scopulariopsis brevicaulis. J. Ferment. Bioeng. 81, 518-523.

13. Kim, B.W.; Choi. J.W.; Yun, J.W. (1998). Selective production of $\mathrm{GF}_{4}{ }^{-}$ fructooligosaccharides from sucrose by a new transfructosylating enzyme. Biotechnol. Lett. 20, 1031-1034.

14. Kurakake, M.; Onoue, T.; Komaki, T. (1996). Effect of pH on transfructosylation and hydrolysis by $\beta$-fructofuranosidase from Aspergillus oryzae. Appl. Microbiol. Biotechnol. 45, 236-239.

15. L'hocine, L.; Wang, Z.; Jiang, B.; Xu, S. (2000). Purification and partial characterization of fructosyltransferase and invertase from Aspergillus niger AS0023. Biotechnol. 81, 73-84.

16. Liu, J.Z.; Zhang, Q.L.; Weng, L.P.; Ji, L.N. (2003). Screening and mutagenesis of Aspergillus niger for the improvement of Glucose-6phosphate dehydrogenase production. Appl. Biochem. Microbiol. 39, 493-496.

17. MacCabe, A.P.; Orejas, M.; Tamayo, E.N.; Villanueva, A.; Ramón, D. (2002). Improving extracellular production of food-use enzymes from Aspergillus nidulans. J. Biotechnol. 96, 43-54.

18. Miller, G.L. (1959). Use of dinitrosalicylic acid reagent for determination of reducing sugar. Anal. Chem. 31, 426-428.

19. Pandey, A.; Nigam, P.; Soccol, C.R.; Soccol, V.T.; Singh, D.; Mohan, R. (2000). Advances in microbial amylases. Biotechnol. Appl. Biochem. 31, 135-152.

20. Patel, V.; Saunders, G.; Bucke, C. (1997). N-Deglycosylation of fructosyltransferase and invertase from Fusarium oxysporum decreases stability but has little effect on kinetics and synthetic specificity. Biotechnol. Lett. 19, 75-77.

21. Rajoka, M.I.; Yasmeen, A. (2005). Improved productivity of $\beta$ fructofuranosidase by a derepressed mutant of Aspergillus niger from conventional and non-conventional substrates. World J. Microbiol. Biotechnol. 21, 471-478.

22. Rubinder, K.; Chadha, B.S.; Singh, N.; Saini, H.S.; Singh, S. (2002). Amylase hyperproduction by deregulated mutants of the thermophilic fungus Thermomyces lanuginosus. J. Ind. Microbiol. Biotechnol. 29, 7074.

23. Sangeetha, P.T.; Ramesh, M.N.; Prapulla, S.G. (2004). Production of fructooligosaccharides by fructosyltransferase from Aspergillus oryzae CFR 202 and Aureobasidium pullulans CFR 77. Process. Biochem. 39, 753-758.

24. Sangeetha, P.T.; Ramesh, M.N.; Prapulla, S.G. (2005). Fructooligosaccharide production using fructosyl transferase obtained from recycling culture of Aspergillus oryzae CFR 202. Process. Biochem. 40, 1085-1088. 
Production of $\beta$-Fructofuranosidase by $A$. oryzae

25. Sheu, D.C.; Lio, P.J.; Chen, S.T.; Lin, C.T.; Duan, K.J. (2001). Production of fructooligosaccharides in high yield using a mixed enzyme system of $\beta$-fructofuranosidase and glucose oxidase. Biotechnol. Lett. 23, 1499-1503.

26. Skowronek, M.; Fiedurek, J. (2003). Selection of biochemical mutants of Aspergillus niger resistant to some abiotic stresses with increased inulinase production. J. Appl. Microbiol. 95, 686-692.

27. Yun, J.W. (1996). Fructooligosaccharides: Occurrence, preparation and application. Enzyme Microb. Technol. 19, 107-117.

28. Yun, J.W.; Kim, D.H.; Song, S.K. (1997). Enhanced production of fructosyltransferase and glucosyltransferase by substrate feeding cultures of Aureobasidium pullulans. J. Ferment. Bioeng. 84, 261-263. 